\title{
Literature Review : Gambaran Tingkat Nyeri Pada Remaja yang Menstruasi
}

\author{
Nila Ayuningtyas ${ }^{1 *}$, Ratnawati ${ }^{2}$ \\ 1,2 Program Studi Sarjana Keperawatan dan Pendidikan Profesi Ners, Fakultas Ilmu Kesehatan \\ Universitas Muhammadiyah Pekajangan Pekalongan, Indonesia. \\ *email: ayuningtyasnila1@gmail.com
}

\begin{abstract}
The period of growth in adolescents is characterized by physical and psychological changes. Girls will experience menstruation and the impact that often occurs is dysmenorrhea (menstrual pain). Dysmenorrhea causes mood disorders in adolescents which will reduce learning motivation. In early adolescents who need adaption, their mental is needed to be ready for the changes which physically and psychologically related to dysmenorrhea. His study aimed to determine the level of pain in adolescents who menstruate. He method used in this research was descriptive with a litetarute review approach. The articles were published in 2011-2021 on Garba Garuda or PubMed. The result obtained according to the inclusion and exclusion criteria were then analyzed using the JBI (Joanna Briggs Institute) instrument. The result of study of the 5 articles with a total of 1,807 respondents showed that the level of menstrual pain was $27,6 \%$ mild pain, $37,2 \%$ moderate pain, and $35,2 \%$ severe pain. The number of adolescents who have moderate pain levels is more that those with mild and severe pain levels
\end{abstract}

Keywords: adolescents, dysmenorrhea, menstrual pain

\begin{abstract}
Abstrak
Masa pertumbuhan pada anak remaja ditandai dengan perubahan fisik dan psikologis. Pada anak perempuan akan mengalami menstruasi dan dampak yang sering terjadi yaitu dismenorea (nyeri haid). Dismenorea menyebabkan gangguan mood pada remaja yang akan menurunkan motivasi belajar. Pada remaja awal yang membutuhkan adaptasi sehingga perlu kesiapan mental mengenai perubahan yang dialami secara fisik dan psikologis terkait dismenorea. Penelitian bertujuan untuk mengetahui gambaran tingkat nyeri pada remaja yang menstruasi. Metode yang digunakan pada penelitian ini adalah deskriptif dengan pendekatan literature review, pencarian artikel pada rentang waktu 10 tahun yaitu dari 20112021 melalui penelusuran didapatkan 4 artikel melalui Garba Garuda dan 1 artikel melalui PubMed. Hasil pencarian sesuai dengan kriteria inklusi dan eksklusi kemudian dianalisa menggunakan instrument JBI (Joanna Briggs Institute), kemudian diolah menggunakan uji Chi-Square dan tidak memenuhi syarat sehingga dilanjutkan menggunakan uji MannWhitney. Hasil penelitian dari ke-5 artikel dengan total responden 1.807 menunjukkan bahwa tingkat nyeri haid yaitu $27,6 \%$ nyeri ringan, $37,2 \%$ nyeri sedang, dan $35,2 \%$ nyeri berat. Dari ke-5 artikel yang telah dianalisa menunjukkan bahwa remaja putri yang berada pada tingkat nyeri sedang lebih banyak dibanding dengan tingkat nyeri ringan dan berat
\end{abstract}

Kata kunci: dismenore, nyeri menstruasi, remaja

\section{Pendahuluan}

Perkembangan merupakan hal yang mutlak terjadi pada individu yang diawali dari proses prenatal, perkembangan pada manusia akan terus berjalan dan semakin luas seiring bertambahnya usia. Setiap fase perkembangan memiliki keistimewaan yang berbeda-beda. Salah satu fase yang menonjol dalam proses perkembangan manusia 


\section{Prosiding Seminar Nasional Kesehatan Lembaga Penelitian dan Pengabdian Masyarakat Universitas Muhammadiyah Pekajangan Pekalongan}

adalah masa remaja yang dimulai pada usia 10-19 tahun menurut WHO (World Health Organization). Secara spesifik masa remaja dibagi menjadi tiga yaitu remaja awal, dimulai dari usia 10-14 tahun, remaja tengah 15-17 tahun, dan remaja akhir 18-24 tahun (Rahman, Naomi \& Pamela, 2020)

Masa pertumbuhan pada anak remaja ditandai dengan perubahan fisik, seperti tinggi badan, payudara membesar pada anak perempuan, suara menjadi berat pada anak laki-laki, pertumbuhan rambut pada kemaluan dan ketiak, serta bagian tubuh lainnya yang membesar atau memanjang. Individu pada tahap ini menandakan bahwa ia sedang memasuki masa pubertas (Rahma, Naomi dan Pamela, 2020)

Masa pubertas pada wanita ditandai dengan haid pertama (menstruasi). Menstruasi adalah perdarahan yang keluar dari uterus yang terjadi pada wanita. Beberapa penelitian menunjukkan bahwa rata-rat usia menstruasi terjadi lebih cepat di Amerika Serikat tahun 2009 sekita 95\% remaja mengalami masa pubertas pada usia 12 tahun, sedangkan di maharashtra India rata-rata usia menstruasi pada remaja 12,5 tahun, 24,92\% menstruasi dini pada usia 10-11 tahun, 64,77\% menstruasi ideal usia 12-13 tahun dan 10,30\% menstruasi lambat 14-15 tahun. Hasil RISKESDAS Indonesia tahun 2010 menunjukkan bahwa rata-rata usia manarche yaitu 13 tahun dengan kejadian lebih awal pada usia kurang dari 9 tahun atau lebih lambat samapi usia 17 tahun (Dewi, 2019).

Dampak dari menstruasi yang sering terjadi adalah nyeri haid (dismenorea) yaitu nyeri menstruasi yang dirasakan di panggul, paha bagian dalam, perut bagian bawah yang menjalar ke punggung, dapat disertai gejala lainnya seperti pusing dan mual. Umumnya dismenorea terjadi 3 tahun pertama setelah manarche. Di Indonesia kejadian dismenorea menunjukkan $64,25 \%$ yang terdiri dari $54,89 \%$ dismenorea primer dan 9,36\% dismenorea sekunder (Pebri, Samsider, dll 2020).

Pada remaja awal yang membutuhkan adaptasi sehingga perlu sikap baik mengenai perubahan yang dialami secara fisik maupun psikologis terkait dismenorea (nyeri haid). Remaja yang merasa terganggu oleh nyeri yang dialami sehingga menghambat aktifitas sehari-hari dan proses pembelajaran menjadi kurang fokus. Oleh karena itu, penulis tertarik untuk melakukan penelitian dengan judul Literature Review : Gambaran Tingkat Nyeri Pada Remaja yang Menstruasi.

\section{Metode}

Dalam penelitian literature review ini menggunakan data sekunder, yakni mengambil data dari artikel penelitian terdahulu. Sumber database yang digunakan dalam penelitian ini yaitu PubMed (https://pubmed.ncbi.nlm.nih.gov/) sebagai situs pencarian artikel internasional. Portal Garuda (https://garuda.ristekbrin.go.id/), dan diberi batasan tahun atau dalam rentan waktu 10 tahun terakhir. kemudian menuliskan kata kunci "adolescence" AND "dysmenorrhea", "remaja" dan "dismenore", kemudian artikel diidentifikasi sesuai topik dan diberi batasan dari tahun 2017-2021 dan didapatkan 1.816 artikel. Kemudian artikel di diseleksi sesuai kriteria menurut kesesuaian judul, abstrak, dan kriteria inklusi didapatkan 5 artikel, yang kemudian di analisa menggunakan instrument JBI (Joanna Briggs Institute) untuk mengetahui kelayakan artikel kemudian diolah menggunakan uji Chi-Square dan tidak memenuhi 


\section{Prosiding Seminar Nasional Kesehatan Lembaga Penelitian dan Pengabdian Masyarakat Universitas Muhammadiyah Pekajangan Pekalongan}

syarat sehingga dilanjutkan menggunakan uji Mann-Whitney untuk mengetahui gambaran tingkat nyeri pada remaja yang menstruasi.

\section{Hasil dan Pembahasan Hasil}

Hasil penelusuran menggunakan 5 artikel nasional maupun internasional dengan pemilihan sesuai kriteria inklusi dan eksklusi. Artikel yang direview menghasilkan 18407 responden. Lima artikel tersebut yaitu dari Ilmi et al, (2017), Marfuah et al., (2018), Misliani et al., (2019), Setiawan et al., (2018), Sderman et al., (2018). Berdasarkan data artikel tersebut kemudian diolah sesuai tujuan penelitian yaitu variabel tingkat nyeri pada remaja yang menstruasi.

\section{Variabel tingkat nyeri menstruasi pada remaja}

Untuk distribusi frekuensi variabel kecemasan pada ke 5 artikel mengkategorikan tingkat nyeri menjadi 3, nyeri ringan, nyeri sedang, dan nyeri berat, berikut hasil analisa :

Tabel 3.1 Distribusi frekuensi tingkat nyeri menstruasi (dismenorea)

\begin{tabular}{ccc}
\hline Tingkat Nyeri & $\mathrm{N}$ & $\%$ \\
\hline Ringan & 498 & 27,6 \\
Sedang & 673 & 37,2 \\
Berat & 636 & 35,2 \\
\hline Total & 1.807 & 100
\end{tabular}

Hasil literatur review dari ke-5 artikel dengan 1.807 responden berdasarkan tingkat nyeri menstruasi (dismenorea) didapatkan hasil $498(27,6 \%)$ nyeri ringan, 673 $(37,2 \%)$ nyeri sedang, dan $636(35,2 \%)$ nyeri berat. Maka dapat disimpulkan bahwa responden yang mengalami tingkat nyeri sedang lebih banyak dibandingkan dengan nyeri ringan dan nyeri berat.

\section{Pembahasan}

Dismenorea adalah nyeri menstruasi yang paling sering dirasakan oleh wanita yang memasuki masa remaja. Hasil literature review dari ke-5 artikel dengan kejadian dismenore menunjukkan hasil $498(27,6 \%)$ nyeri ringan, $673(37,2 \%)$ nyeri sedang, dan $636(35,2 \%)$ nyeri berat.Yang artinya responden lebih banyak pada kategori tingkat nyeri sedang. Dampak nyeri haid menyebabkan terganggunya aktivitas harian selama 1-3 hari setiap bulannya pada setiap wanita (Rima dan Istri, 2020).

Menurut Ilham Brahmana dan Hendy (2020) dismenorea merupakan nyeri siklik yang terjadi saat menstruasi dan mencangkup masalah sosial-ekonomi. Jutaan jam kerja pada wanita dan proses pembelajaran pada remaja hilang karena sulit untuk berkonsentrasi. Belajar membutuhkan fisik yang sehat karena hal tersebut akan mempengaruhi seluruh bagian tubuh sehingga aktivitas belajar tidak menurun.

Nyeri pada saat menstruasi dapat disebabkan oleh faktor fisiologis dan faktor psikologis. Faktor fisiologis karena tubuh belum mampu beradaptasi dengan perubahan hormon dan perubahan anatomi yang belum matang. Faktor psikologis karena remaja 


\section{Prosiding Seminar Nasional Kesehatan 2021 Lembaga Penelitian dan Pengabdian Masyarakat Universitas Muhammadiyah Pekajangan Pekalongan}

belum siap secara mental untuk menghadapi dampak menstruasi. Perasaan takut dan cemas dapat menimbulkan nyeri saat menstruasi. (Gunawati \& Nisman, 2021)

Adapun faktor psikis terjadinya dismenorea yaitu konstitusional (anemia, kelemahan, TBC), obstertic (cervic sempit, hyperanteflexio, retroflexio), dan endokrin (peningkatan kadar prostaglandin, hormon steroid seks, kadar vasopresis yang tinggi). Faktor psikis sangat berpengaruh terhadap dismenorea karena nyeri dapat tibul atau semakin parah karena faktor (Nurul dan Ruly 2020).

Gejala terjadinya frekuensi dismenorea pada remaja yang merasakan tingkat nyeri berat disebabkan karena adanya gejala nyeri perut bagian bawah seperti kram, sedangkan pada remaja yang berada di tingkat nyeri sedang disebabkan karena adanya nyeri panggul yang menjalar ke punggung dan paha bagian dalam. Nyeri haid dapat diukur menggunakan skala angka (Numeric Rating Scale) 1-3 nyeri ringan, 4-6 nyeri sedang, 7-9 nyeri berat, dan 10 nyeri tak terkontrol (Anang \& Rina, 2018).

Beberapa remaja saat menstruasi kemungkinan tidak seluruhnya mengalami kram tetapi untuk remaja lain nyeri haid sudah menjadi siklus bulanan mereka. Nyeri haid (dismenorea) adalah kejadian yang normal. Akan tetapi nyeri haid juga dapat berhubungan dengan penyakit atau ginekologi. Apabila remaja merasakan nyeri yang parah, maka pastikan untuk pergi ke dokter membahas masalah ini (Andri, 2011).

Penanganan yang dapat dilakukan untuk mengobati nyeri haid (dismenorea) adalah memberi informasi lebih jelas tentang dismenorea. Semakin remaja paham tentang dismenorea maka remaja dapat memberi toleransi pada dirinya saat mengalami menstruasi. Hal tersebut mempengaruhi remaja yang mengalami intensitas dismenorea berat dapat menahan nyeri yang dirasakan sehingga dapat menurunkan tingkat dismenorea yang dirasakan. Penanganan lain yang dapat dilakukan seperti pemberian obat analgetik terapi hormonal, terapi nonsteroid antiprostaglandin, dan diltasi kanalis servikalis (Prastika et al., 2019)

\section{Kesimpulan}

Dari ke-5 artikel yang telah ditelaah menggunakan pendekatan literature review dengan kejadian tingkat nyeri haid atau dismenorea pada remaja menunjukkan hasil $498(27,6 \%)$ nyeri ringan, $673(37,2 \%)$ nyeri sedang, dan $636(35,2 \%)$ nyeri berat.Yang artinya responden lebih banyak mengalami tingkat nyeri sedang.

\section{Referensi}

[1] Andri priyatna (2011). My Little Angel. Gramedia : Jakarta

[2] Anang Setiana dan Rina Nuraeni. (2018). Riset Keperawatan. LovRinz Publishing : Cirebon

[3] Deswani,Ulty D \& Yuli M (2018). Asuhan Keperawatan Prenatal dengan Pendekatan Neurosains. Wineka Media : Malang

[4] Dewi Novidiantoko (2019). Asuhan Keperawatan Jiwa Masalah Psikososial di Pelayanan Klinis dan Komunitas. CV Budi Utama

[5] Eddy Cahyadi. (2016). Dear Girl. Bintang Wahyu : Jakarta 


\section{Prosiding Seminar Nasional Kesehatan Lembaga Penelitian dan Pengabdian Masyarakat Universitas Muhammadiyah Pekajangan Pekalongan}

[6] Endah M, Diani Octaviyanti H, Rizka Esti S (2020). Kesehatan Reproduksi Wanita. Literasi Nusantara : Batu

[7] Fillah Fitrah D. (2014). Permasalahan Gizi pada Remaja Putri. Yogyakarta : Graha IImu

[8] Gunawati, A., \& Nisman, W. A. (2021). Faktor-Faktor yang Berhubungan dengan Tingkat Dismenorea di SMP Negeri di Yogyakarta. 8(1). https://doi.org/10.22146/jkr.56294

[9] Heni S, Kartika W, Zulfikar B \& Ahmad A (2018). Akupresur Untuk Kesehatan Wanita Berbasis Penelitian. UNIMMA PRESS

[10] Ilham Brahmana \& Hendy H (2020). Ginekologi Praktis Komprehensif. Airlangga University Pres

[11] Ilmi, M. B., Fahrurazi, \& Mahrita. (2017). Dysmenorrhea As a Stress Factor in Teenage Girls of Class $X$ and XI In Kristen Kanaan High School Banjarmasin. Jurnal Kesehatan Masyarakat Khatalustiwa.

[12] Irfana (2021). Faktor Determinan Kejadian Menopause. CV Media SAINS Indonesia : Bandung

[13] Khairunnisa Syamsu. ( 2021). Bimbingan Konseling Kesehatan Reproduksi Remaja. Media sains indonesia.

[14] Marfuah dan mayasari. (2018). Hubungan Status Nutrisi Dengan Nyeri Menstruasi. Hubungan Status Nutrisi Dengan Nyeri Menstruasi Pada Remaja Smp Negeri 16 Bandung, 5(2), 82-87.

[15] Maria Florians P, Elfina Natalia, dan Eka Antika (2020). Kesehatan Reproduksi Remaja Putri. Samarinda

[16] M Ilham, Brahmana A \& Hendy H (2020). Ginekologi Praktik Komprehensif. UNAIR : Mulyorejo Surabaya

[17] Misliani, A., Mahdalena, \& Syamsul, F. (2019). Penanganan Dismenore Cara Farmakologi dan Nonfarmakologi. Jurnal Citra Keperawatan, ス1), 23-32.

[18] Nessi M, Maryanah \& Willa F (2019). Kesehatan Reproduksi Remaja. Wineka Media : Malang

[19] Nurul Hidayatun J dan Ruly Prapitasai. (2020). Buku Ajar Kesehatan Reproduksi Keluarga Berencana. CV Adanu Abimata : IndramayuGunawati, A., \& Nisman, W. A. (2021). Faktor-Faktor yang Berhubungan dengan Tingkat Dismenorea di SMP Negeri di Yogyakarta. 8(1). https://doi.org/10.22146/jkr.56294

[20] Prastika, A. W., Sari, G. M., Hardianto, G., Kedokteran, F., \& Airlangga, U. (2019). HUBUNGAN DISMENOREA PRIMER DENGAN AKTIVITAS BELAJAR PADA SISWI SMAN 8 SURABAYA CORRELATION BETWEEN PRIMARY DYSMENORRHEA AND Pada bidang pendidikan dilakukan program wajib sekolah , Kartu Indonesia Pintar , ( Shidiq , 2018 ). Dalam peningkatan kualitas pen. 3(2), 107-113. https://doi.org/10.20473/imhsj.v3i2.2019.107-113 


\section{Prosiding Seminar Nasional Kesehatan 2021 Lembaga Penelitian dan Pengabdian Masyarakat Universitas Muhammadiyah Pekajangan Pekalongan}

[21] Gunawati, A., \& Nisman, W. A. (2021). Faktor-Faktor yang Berhubungan dengan Tingkat Dismenorea di SMP Negeri di Yogyakarta. 8(1). https://doi.org/10.22146/jkr.56294

[22] Pebri Wanita P, Samsider Sitorus, dkk (2020). Ilmu Obstetri dan Ginekologi Untuk Kebidanan. Yayasan Kita Menulis

[23] Rahman H, Naomi S \& Pamela Hendra H (2021). Remaja Sejahtera Remaja Nasionalis. Yogyakarta : CV Andi Offest

[24] Rima Wirenviona dan A.A. Istri dalem chintya R (2020). Edukasi kesehatan Remaja. Airlangga University Press : Surabaya

[25] Rina Nuraeni (2017). Keperawatan Maternitas. LovRinz Publishing : Cirebon

[26] Setiawan, S. A., \& Lestari, L. (2018). Hubungan Nyeri Haid (Dismenore) dengan Aktivitas Belajar Sehari-Hari Pada Remaja Putri Kelas VII Di SMPN 3 Pulung. Jurnal Delima Harapan, 5(1), 24-31. https://doi.org/10.31935/delima.v5i1.5

[27] Sderman, L., Edlund, M., \& Marions, L. (2019). Prevalence and impact of dysmenorrhea in Swedish adolescents. Acta Obstetricia et Gynecologica Scandinavica, 98(2), 215-221. https://doi.org/10.1111/aogs.13480

[28] Shilphy A. Octavia (2020). Motivasi Belajar dalam Perkembangan Remaja. Sleman : CV Budi Utama

[29] Sri Bulan M, Nuryani Y. Rustaman \& Saefudin (2019). Selamat Datang Masa Remaja. Sleman : CV Budi Utama

[30] Taufan \& Bobby. (2017). Masalah Kesehatan Reproduksi Wanita. Yogyakarta : Nuha Medika

[31] Tri Ratnaningsih, Sri Indatul \& Tri Peni. (2019). Tumbuh Kembang dan Stimulasi. Sidoarjo : Indomedia Pustaka

[32] Wahyu P., \& Siti F. (2015). Keperawatan Maternitas. Yogyakarta : Nuha Medika 